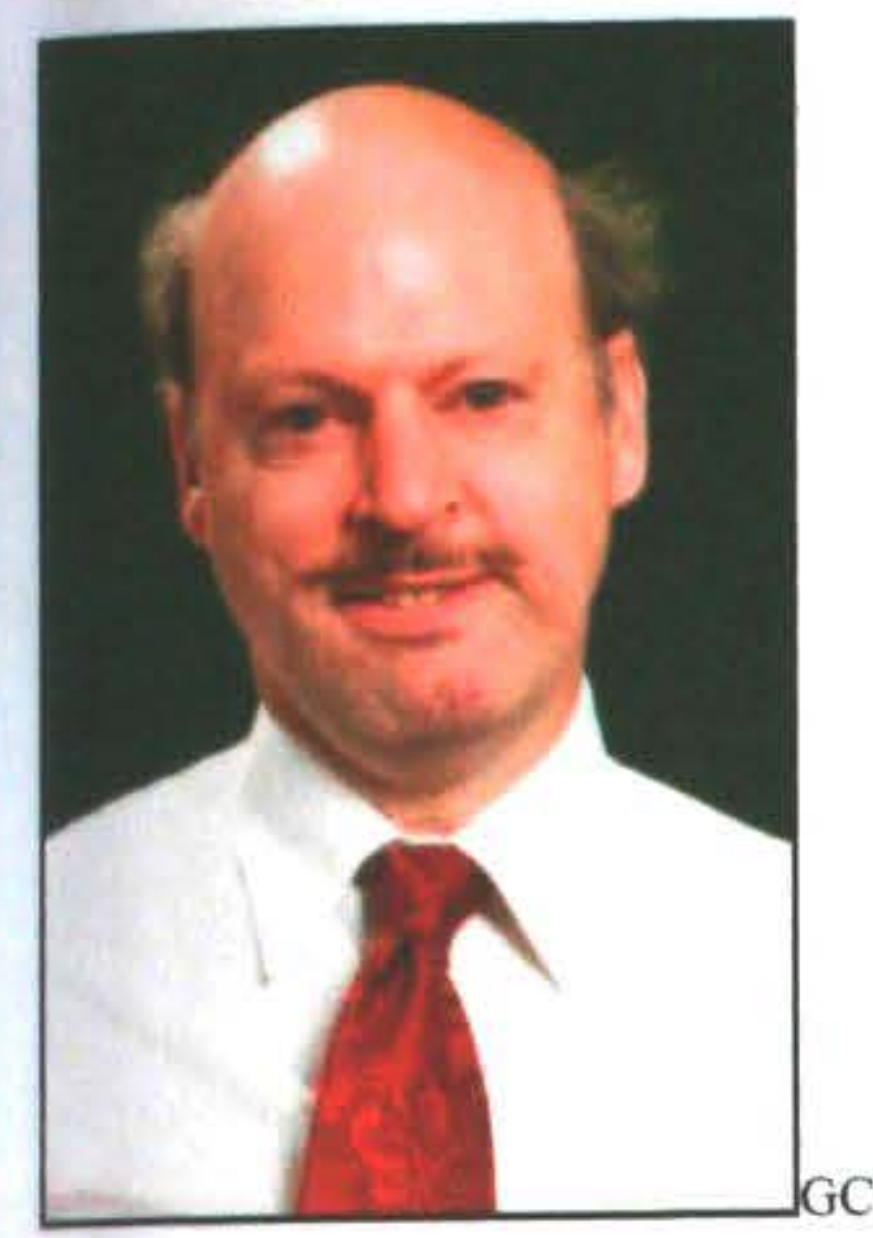

\section{THE DEEWR MONTHLY LEADING INDICATOR OF EMPLOYMENT FOR AUSTRALIA - A VIEW FROM THE INSIDE}

\section{Greg Connolly and Jan Lee}

\author{
Research Analysis and Evaluation Group, \\ Department of Education, Employment \\ and Workplace Relations (DEEWR)
}

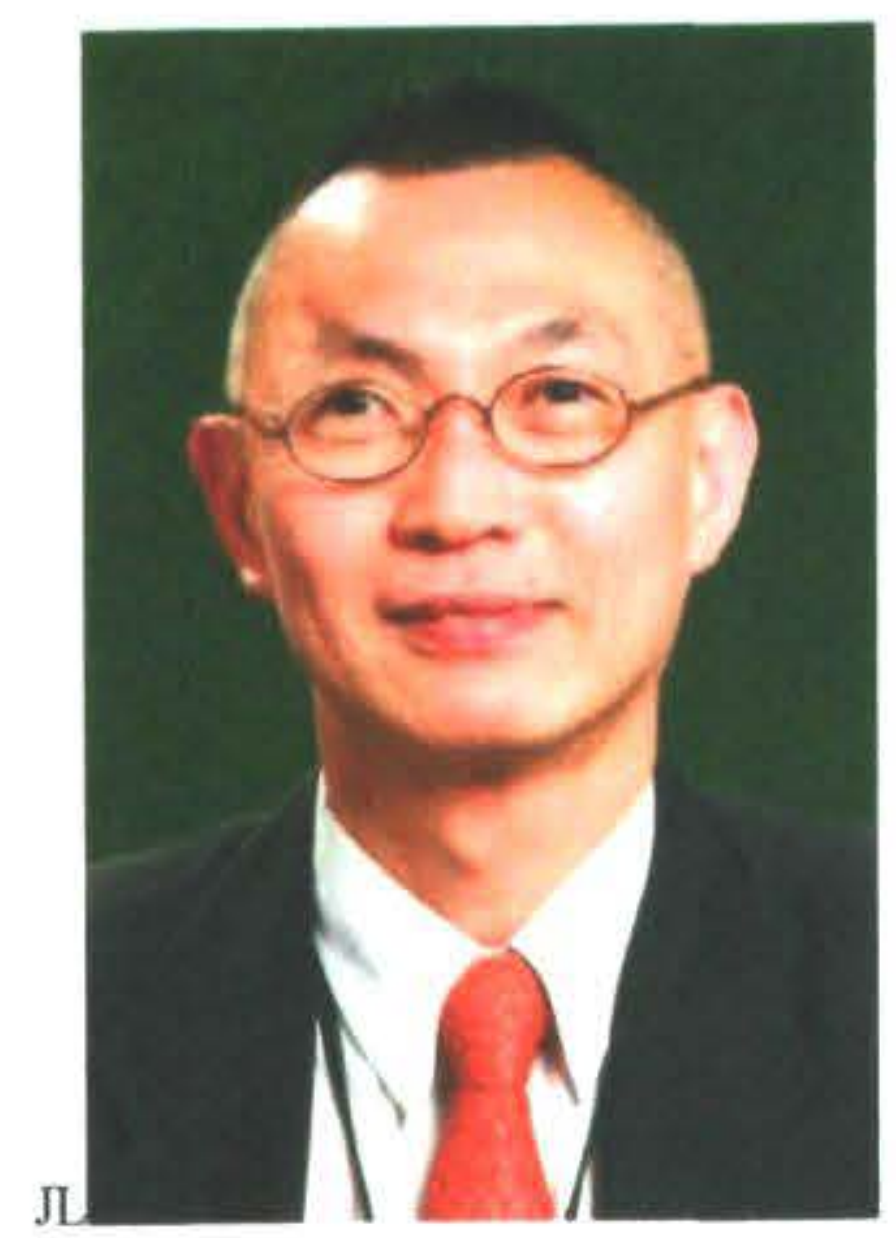

\begin{abstract}
The new DEEWR Monthly Leading Indicator of Employment for Australia has been in operation since July 2007. While it is too early to conduct a proper evaluation on its performance since it has only been released for around a year and a half, it is an opportune time to make some comments on how it has been performing.

There has only been one turning point in the Indicator and in cyclical employment during this time - a peak in the Indicator in Jamuary 2008, followed by a peak in cyclical employment in April 2008. While the peak in cyclical employment was correctly predicted by the Indicator, the lead time was only three months, which is insufficient time to be really useful for policy or program responses. The three components of the Indicator with the highest weightings also had a lead time of around three months with cyclical employment.
\end{abstract}

It is not feasible to conduct an up-to-date comparison with the previous version of the Department's Leading Indicator of Employment. This is because one of the components of the former Indicator was the ABS Job Vacancies series, which is no longer released by the ABS.

The performance of the Indicator in the context of the Global Financial Crisis is discussed in this paper. There are many series that are newly being monitored by economic analysts in Australia to get a better understanding of the Global Financial Crisis and how it is likely to affect Australia. Examples of such series are US housing starts and established house prices, sub-prime mortgage delinquency rates in the USA, the US Treasury-Eurodollar interest rate spread and yield curve and the Baltic Exchange Dry Index of shipping freight rates. While consideration could be given to including offshore indicators in a future version of the Indicator, it would be problematic to attempt to include most of them at this stage.

\section{Introduction}

The new DEEWR Monthly Leading Indicator of Employment for Australia has been publicly released since July 2007 and is available on the internet at:

www.workplace.gov.au/workplace/Publications/LabourM arketAnalysis/LeadingIndicatorEmployment/

Connolly and Lee (1995) provide an analysis and explanation of the process used in developing the new DEEWR Monthly Leading Indicator of Employment.
The movements in this Indicator are shown in Figure 1 below.

There has only been one turning point in the Indicator and in cyclical employment during this time - a peak in the Indicator in January 2008, followed by a peak in cyclical employment in April 2008.

While it is too early to conduct a proper evaluation on its performance since it has only been released for around a year and a half, it is an opportune time to make some comments on how it has been performing. 


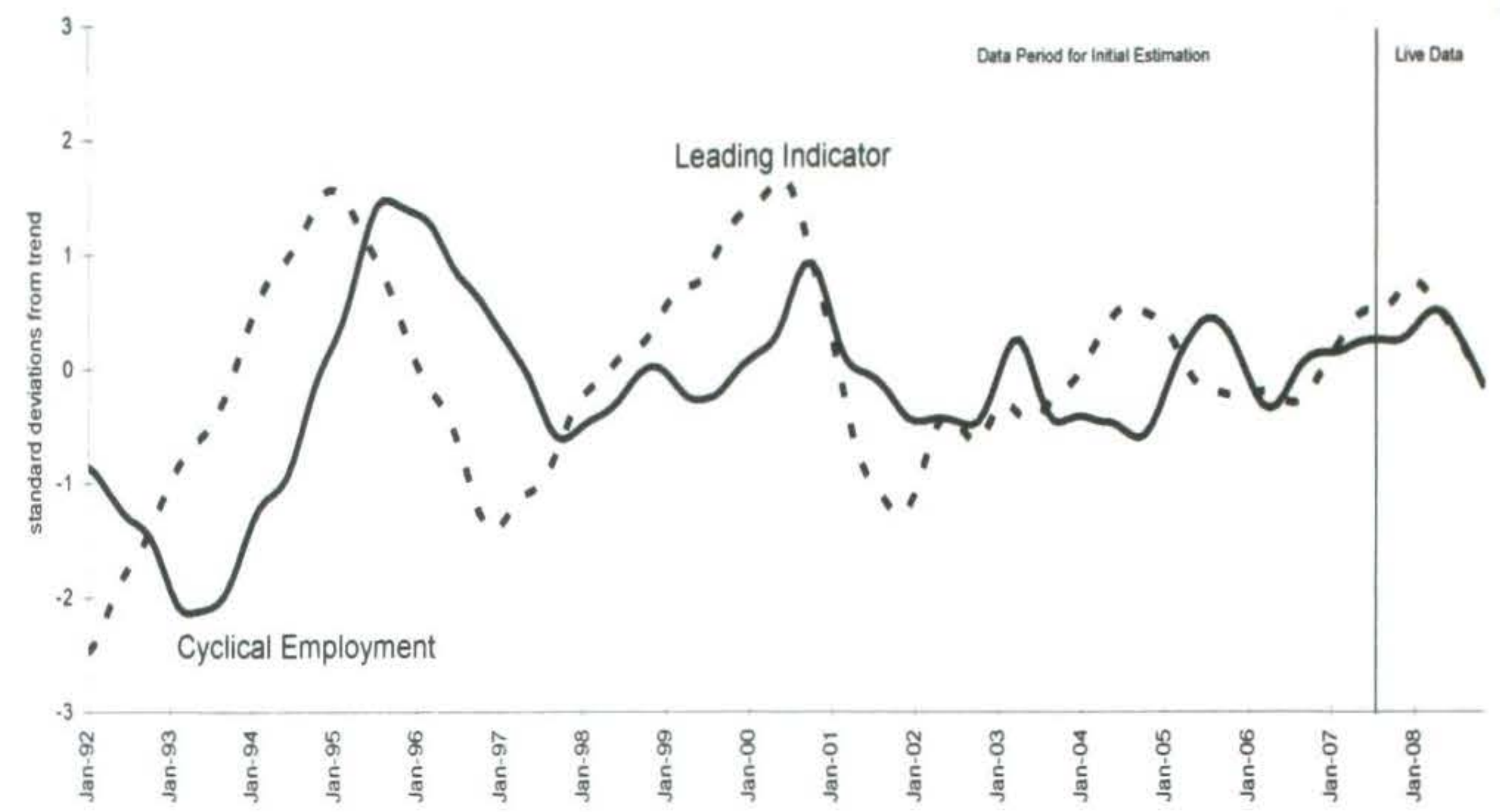

Sources: Cyclical Employment: calculated in EEIS, DEEWR from ABS monthly Labour Force Survey Data; Leading Indicator of Employment: calculated in EEIS, DEEWR from data on its four components as explained in Appendix A.

\section{Movements in the Indicator's Component}

While the peak in cyclical employment was correctly predicted by the Indicator, the lead time was only three months, which is insufficient time to be really useful for policy or program responses. This is especially the case as, by convention, it takes six consecutive monthly movements in a different direction from the Indicator's previous direction to confirm a peak or a trough in the indicator. Obviously, a lead time of three months is only half the time needed to confirm a peak or a trough.

It is not feasible to conduct an up-to-date comparison with the previous version of the Department's Leading Indicator of Employment. This is because one of the components of the former Indicator was the ABS Job Vacancies series, which is no longer released by the ABS.

However, one way of drilling down into the performance of the new DEEWR Monthly Leading Indicator of Employment for Australia is to compare the performance of its four components with cyclical employment. This is because the Leading Indicator is a weighted average of its four components.

These components are compared in descending order of their weightings in the Indicator. The first component to compare is the ANZ Newspaper Job Ads series, which has a weight of 44.3 per cent in the Indicator. Cyclical components of this series and employment are shown in Figure 2.
In terms of lead times since the new Indicator was released in July 2007, the ANZ Newspaper Job Ads series does only slightly better than the overall Indicator, with a lead time of four months.

The Westpac-Melbourne Institute Leading Index of Economic Activity has the second-highest weighting in the DEEWR Monthly Leading Indicator of Employment, with a weight of 24.1 per cent. Cyclical components of this series and employment are shown in Figure 3.

The lead time is three months between the latest peak in the cyclical component of the Leading Index of Economic Activity and the latest peak in the cyclical component of employment. This is the same as for the overall Leading Indicator.

The Dun and Bradstreet Employment Expectations Index is entered into the DEEWR Monthly Leading Indicator of Employment with a lag of 12 months. While the current value of this Index also leads employment in a bivariate relationship, this effect is dominated by other variables when the other three components of the Leading Indicator are added to the analysis. While this variable has the third highest weighting in the Leading Indicator, its weight ( 22.4 per cent) is very close to that of the second-highest weighted component (the WestpacMelbourne Institute Leading Index of Economic Activity).

The relationship between the cyclical components of the 12-month-lagged value of the Dun and Bradstreet Employment Expectations Index and employment are shown in Figure 4. 
Figure 2: Cyclical components of ANZ Newspaper Job Ads and Employment

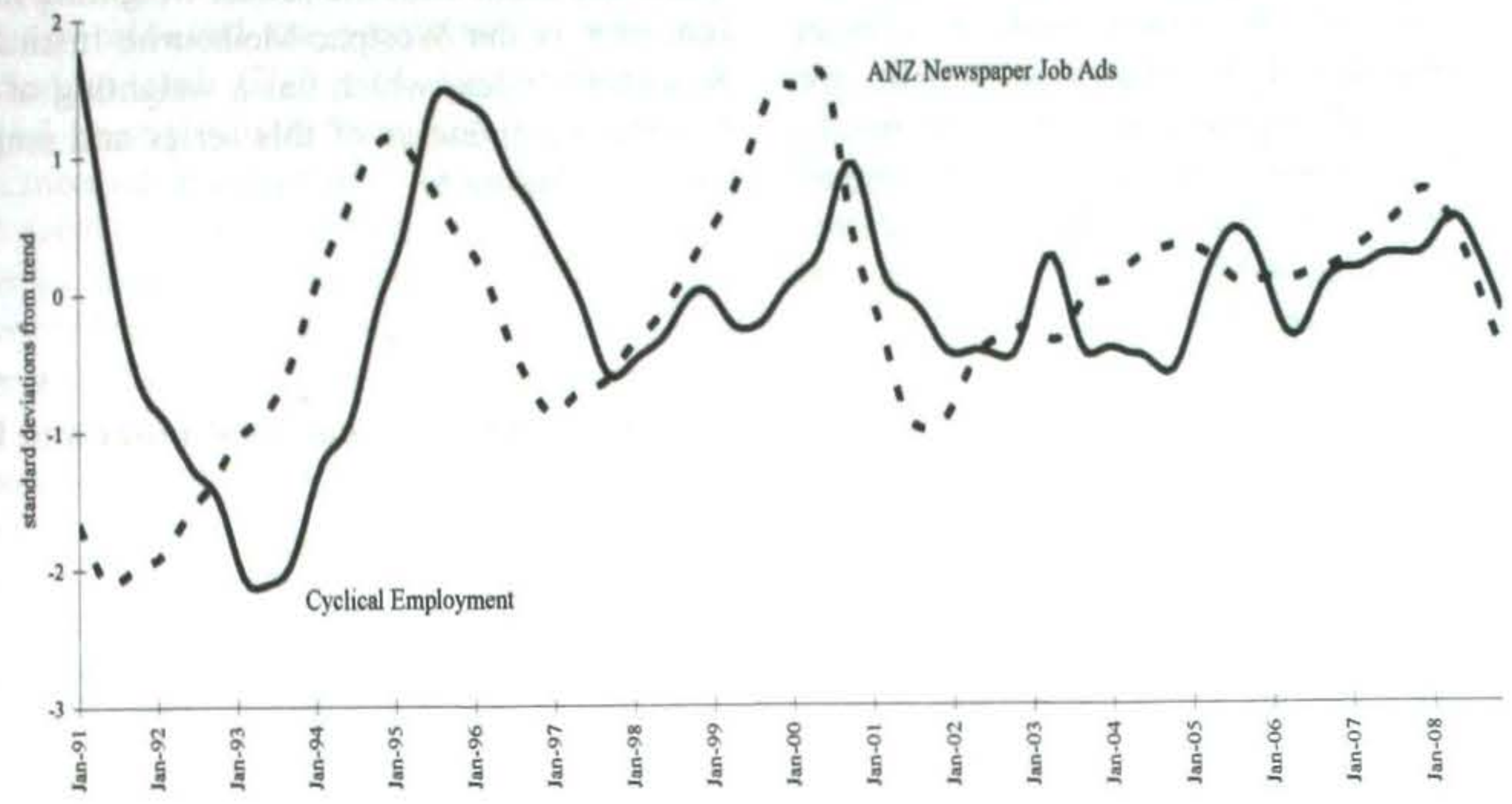

Figure 3: Cyclical components of the Westpac-Melbourne Institute Leading Index of Economic Activity and Employment

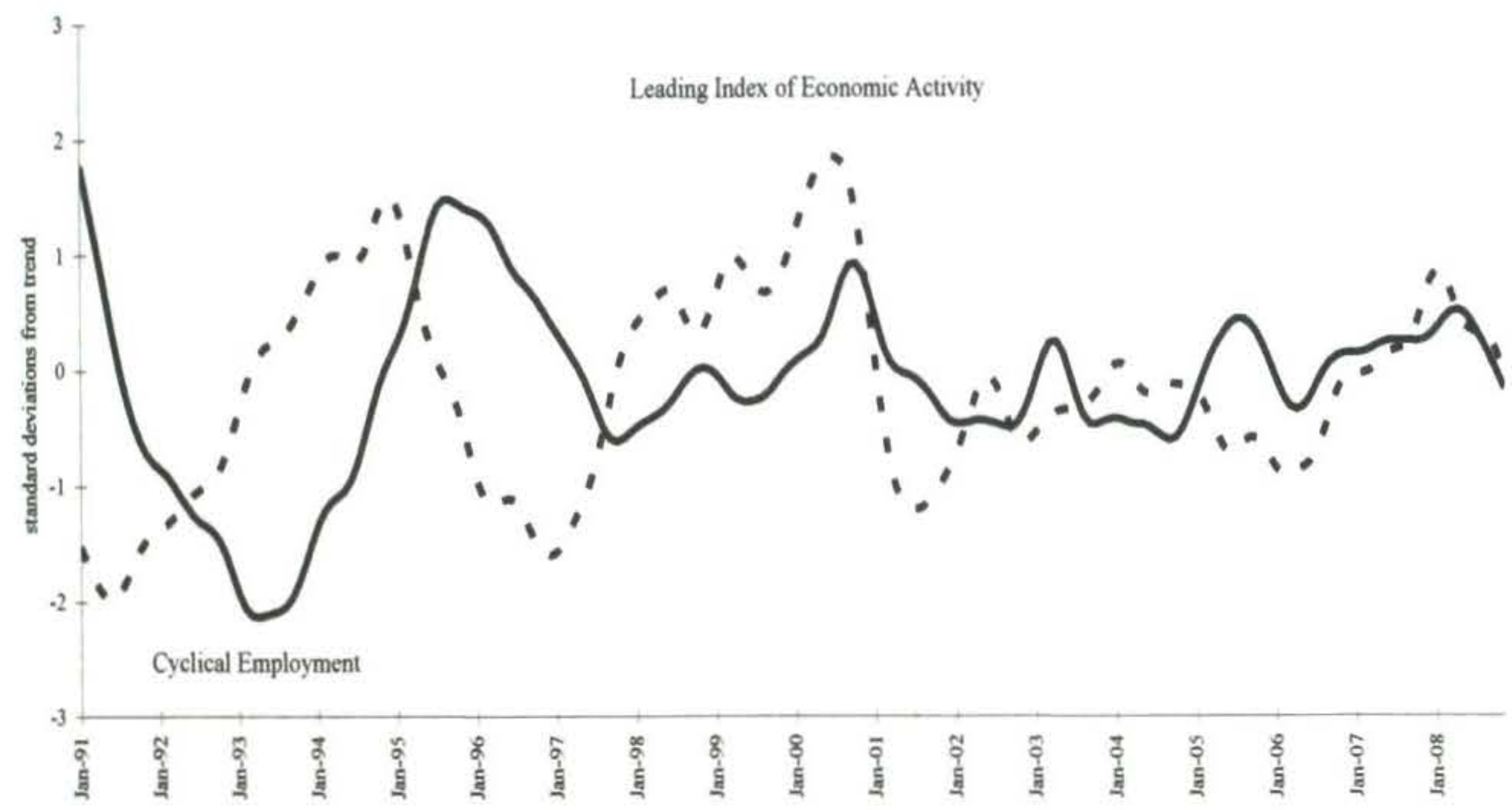

Figure 4: Cyclical components of the Dun and Bradstreet Employment Expectations Index (lagged 12 months) and Employment

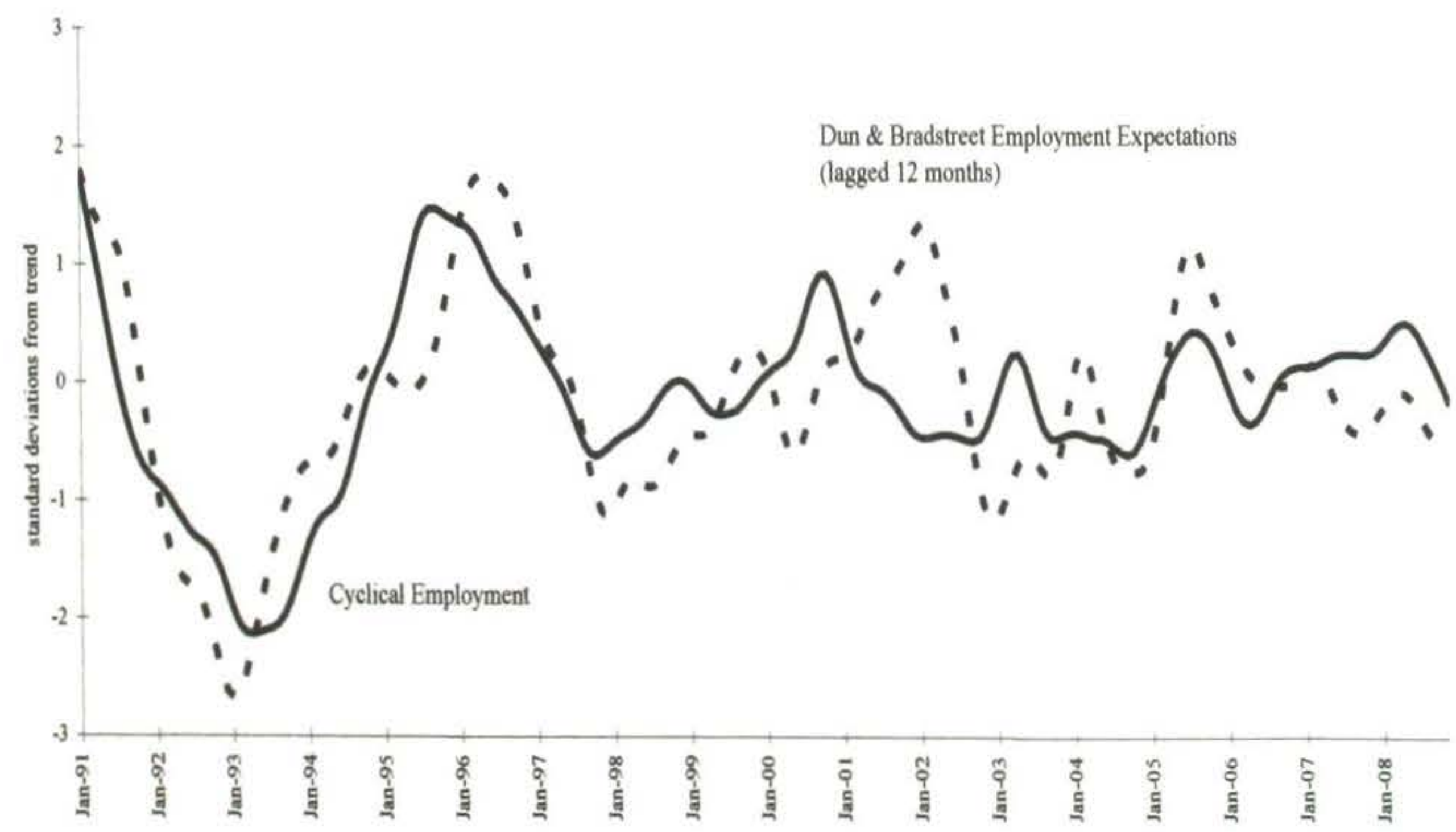

Sources: Cyclical Employment: calculated in EEIS, DEEWR from ABS monthly Labour Force Survey Data; Leading Indicator of Employment: calculated in EEIS, DEEWR from data on its four components as explained in Appendix A. 
The lead time between the cyclical values of the 12month-lagged value of the Dun and Bradstreet Employment Expectations Index and employment, for the latest peak in cyclical employment is only one month, since the cyclical component of the 12-month-lagged value of the Dun and Bradstreet Employment Expectations Index peaked in March 2008, while cyclical employment peaked in April 2008.
The component with the lowest weighting in the Leading Indicator is the Westpac-Melbourne Institute Consumer Sentiment Index, which has a weighting of 9.2 per cent. Cyclical components of this series and employment are shown in Figure 5.

Figure 5: Cyclical components of the Westpac-Melbourne Institute Consumer Sentiment Index and Employment

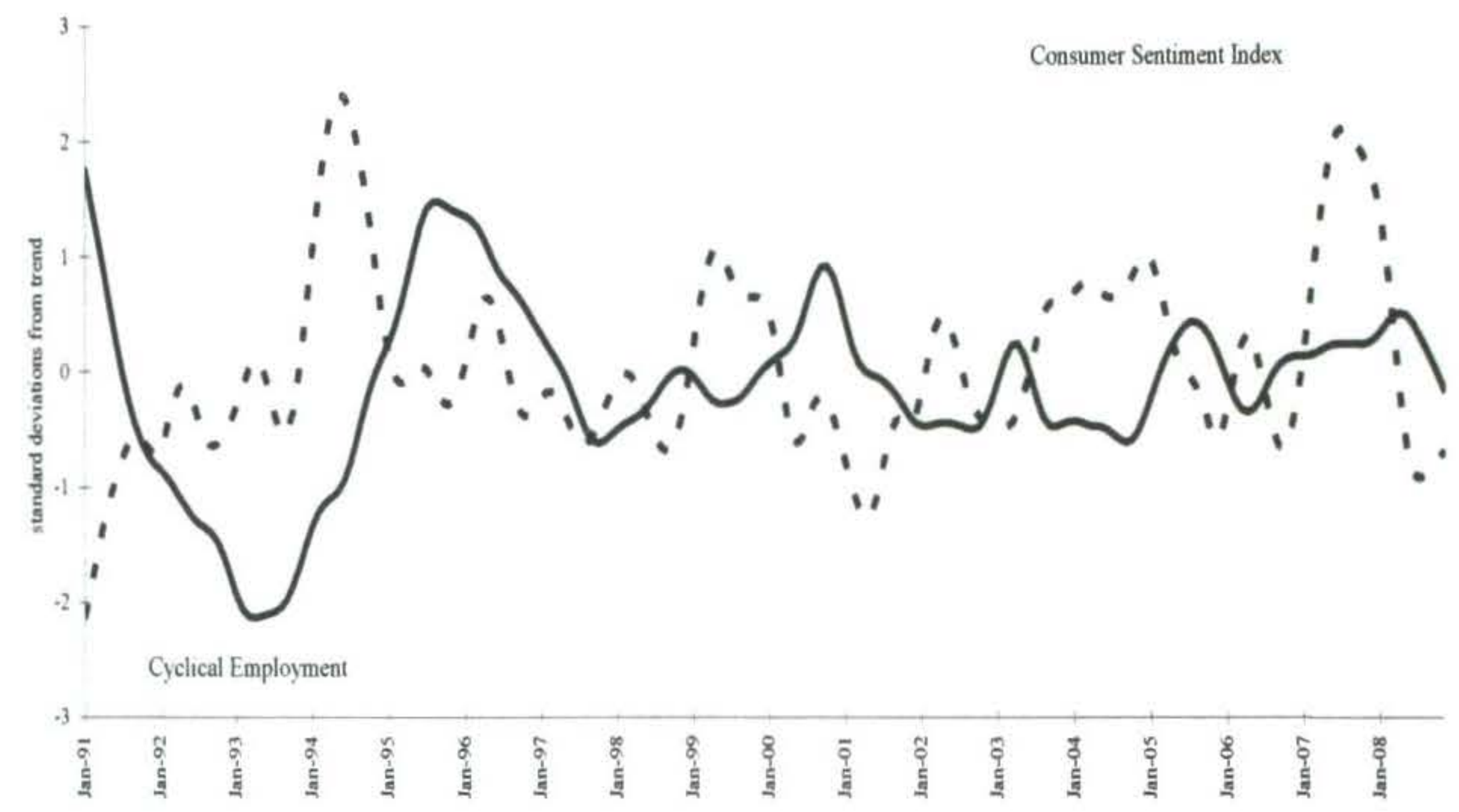

Sources: Cyclical Employment: calculated in EEIS, DEEWR from ABS monthly Labour Force Survey Data; Leading Indicator of Employment: calculated in EEIS, DEEWR from data on its four components as explained in Appendix A.

The lead time between the cyclical values of the Westpac-Melbourne Institute Consumer Sentiment Index and employment, for the latest peak in cyclical employment is nine months, since the cyclical component of the Westpac-Melbourne Institute Consumer Sentiment Index peaked in July 2007, while cyclical employment peaked in April 2008.

While this component was the only one with a really useful lead time for the latest turning point in cyclical employment, it had only a small influence on the overall lead time because it only has a weighting of 9.2 per cent in the Leading Indicator. In addition, as can be seen from Figure 5, it would not be worthwhile to rely too much on this Index as a leading indicator of employment, because its cyclical component has had many more turning points than cyclical employment since the early 1990s. In other words, it has too many false signals of turning points to be reliable as an individual leading indicator of employment.

The main implication of this analysis is that there does not appear to be much, if anything, to be gained by dropping one of the current four series from the Indicator or altering the weights on the four components (for example, by changing from using weights based on regression coefficients to using equal weightings for each series), in order to increase the lead time with cyclical employment.

\section{The Global Financial Crisis}

The global financial turmoil has severely deflated asset prices around the world, undermined investor confidence and constrained the normal flow of finance to business and investment. While the situation remains extremely fluid, the rapid and substantial deflation of asset prices thus far, together with the heightening uncertainty over the short-term economic outlook, have weighed down on the four existing components of the Leading Indicator of Employment.

This crisis began with the defaulting of the US Subprime mortgage loan contracts around mid- 2007. This in turn triggered a chain reaction of defaults on financial derivative contracts that are linked to Subprime mortgage loans. Contagion spread to almost every form of financial derivative contracts globally. The initial unwinding of derivative contracts linked to Subprime mortgages led to a generalised housing market meltdown in the US, and general equity price deflation, with similar repercussions across global markets. The ensuing risk aversion and "flight to quality" of investors globally (i.e., investor flight to the safety of the US dollar generally and to US Treasuries specifically) became pervasive across the world. 
Since mid-2007, the global financial crisis has had a widespread effect on most markets in both the developed and developing world and on variables in the real economy, including real GDP and its components, employment and unemployment. Some of the variables that have been most adversely affected have been interest rate spreads (such as the difference between the eurodollar London inter-bank offer rate (or LIBOR) and the US Treasury interest rate of the same maturity generally three months is used and this series is known as the TED spread), share price indexes in many countries around the world, house prices and other housing variables in the USA, UK, and selected other countries, the Baltic Dry Index of shipping freight rates, and selected commodity prices. Other variables, such as world gold prices, have been less adversely affected, generally because they have been considered to be a safe haven in the financial turmoil.

Two typical series which reflect the global financial crisis are now examined to see how their cyclical components line up with the cyclical component of employment in Australia and whether they would be potential candidates for adding to a possible new version of the DEEWR Leading Indicator of Employment.

As the crisis originated in the US with the bursting of the housing bubble and this had a downward effect on established house prices in that country, we considered the monthly average (median) house price in the US as a possible component. Cyclical components of this series and employment are shown in Figure 6.

\section{Figure 6: Cyclical components of the Median House Price in the US and Australian Employment}

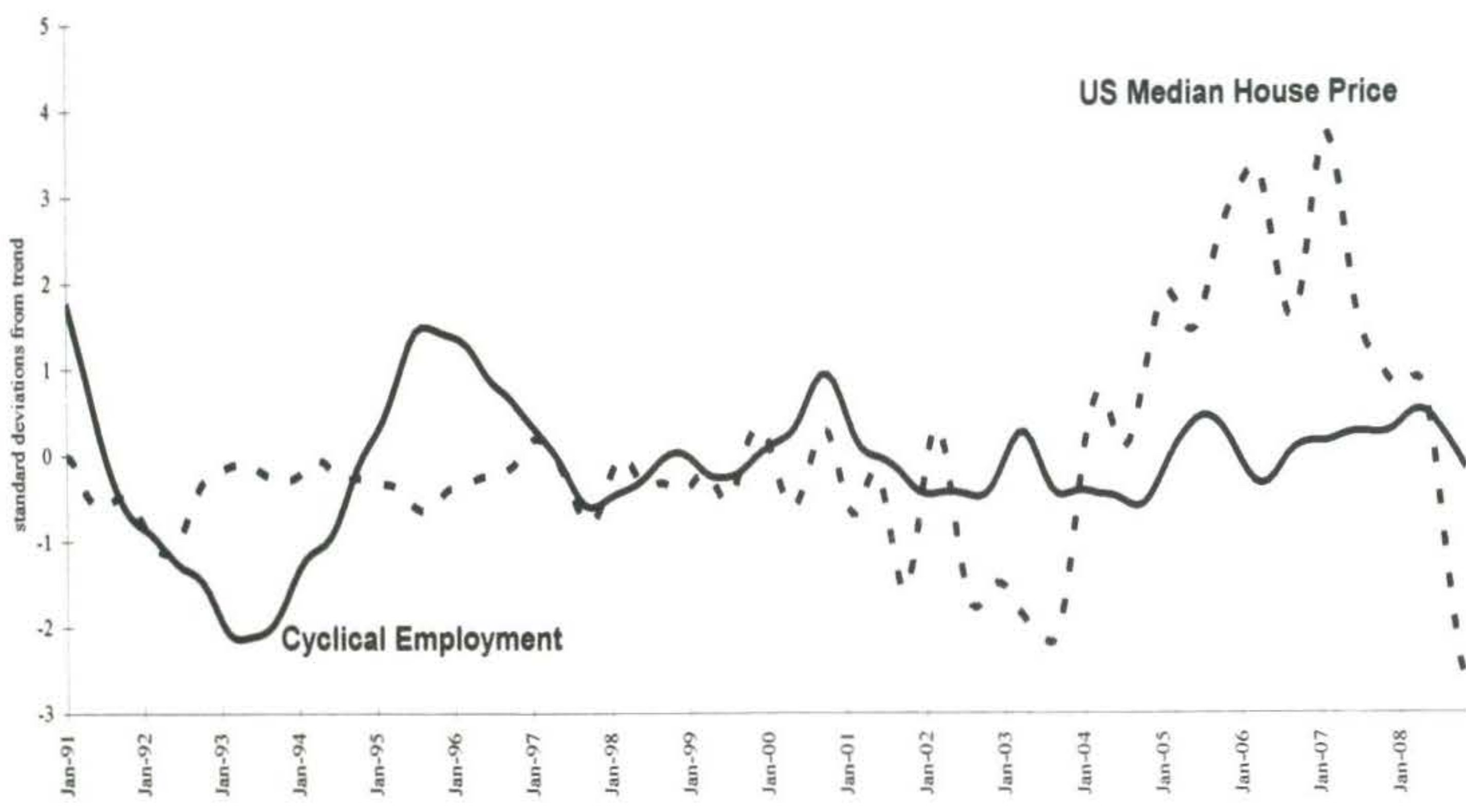

from US data available from http://www.economagic.com/em-cgi/data.exe/cenc $25 / \mathrm{c} 25 \mathrm{~m} 01$ \#Data

As can be seen from Figure 6, using the period from the early 1990s to the latest available month in 2008, the US median housing price series would not yet be a suitable candidate for use as a leading indicator of cyclical employment in Australia. This is because it does not have a consistent and stable lead-lag relationship with the cyclical component of Australian employment. A noteworthy feature of the relationship that can be seen from Figure 6 is that the cyclical amplitude of the US housing price series was less than that of Australian employment in the $1990 \mathrm{~s}$, but this relativity was reversed in the 2000 s. In particular, the latest peak in the cyclical component of the US median house price series occurred in February 2007 and was 3.7 standard deviations above the long-term trend. This was well above any of the other peaks in the 1990s or so far in the 2000s. While it has been followed by the latest peak in cyclical employment in Australia in April 2008, the latter peak is just below 0.5 standard deviations above long-term trend and as such is not a particularly large peak.
In addition, there have been substantially more turning points in the cyclical component of the US housing price series than in the cyclical component of Australian employment. This means that if the US housing price series were to be used as an individual leading indicator of Australian employment, it would give too many false signals of turning points.

The latest value of the cyclical component of the US median house price series (for November 2008) is the lowest since January 1991 at 2.7 standard deviations below the long-term trend. So while this could have adverse implications for Australian employment in the near future, it is not yet appropriate to attempt to add this series to the DEEWR Leading Indicator of Employment. It would be appropriate, however, to continue to monitor this series as a separate exercise. 
There are a number of other indicators of the global financial crisis that are likely to have exhibited similar patterns to that of the US median house price series; that is, not shown much cyclical amplitude until very recently. As examples, many of the interest rate spreads, such as the TED spread, have been relatively stable up until the second half of 2007 but have widened substantially around September 2008. The recency of these movements means that it would be too early to attempt to include them in the DEEWR Leading Indicator of Employment.

Another potential component series, which also reflects the genesis of the global financial crisis, is US Housing Starts. Cyclical components of this series and employment are shown in Figure 7.

\section{Figure 7: Cyclical components of US Housing Starts and Australian Employment}

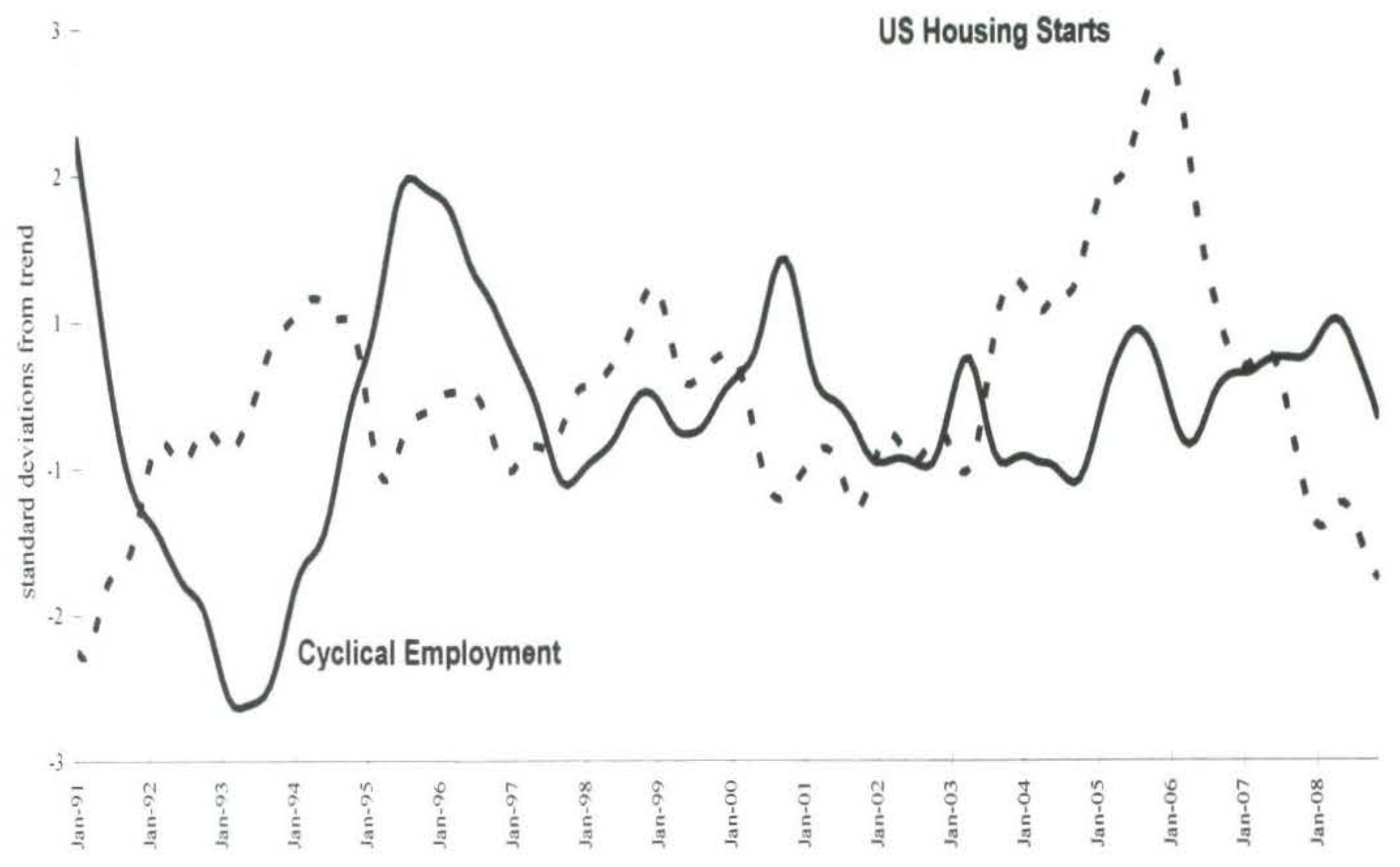

Source: Cyclical Employment: calculated in EEIS, DEEWR from ABS monthly Labour Force Survey Data; US Housing Starts: calculated in EEIS, DEEWR from US data available from http://research.stlouisfed.org/fred2/series/HOUST.

This series would be a better candidate for use as a leading indicator of cyclical employment in Australia than the US median house price series. Since January 1991, there has been a fairly consistent lead time of around $1 \frac{1}{2}$ to $1 \frac{3 / 4}{4}$ years between the cyclical components of US housing starts and Australian employment. Such a lead time would be quite useful for policy purposes. However, the lead time between the latest peaks in each series is longer than average at 28 months. There is a better matching of the cyclical amplitudes between these two series than between US median house prices and Australian employment. Also, the cyclical component of US housing starts does not appear to provide an excessive number of false signals of turning points, with respect to the cyclical component of Australian employment.

\section{Conclusions}

The new DEEWR Leading Indicator of Employment has been performing moderately well since it was released in July 2007. It has been relatively reliable in its monthly movements and has correctly predicted the peak in cyclical employment in April 2008 (which is the only turning point since the new Indicator was released).
However, the lead time between the cyclical peaks in the Indicator and employment was only three months, which is too short to be of substantial use for policy or program responses.

This does not necessarily mean that the Indicator should be abandoned. As can be seen from Figure 1, and is a well known feature of many leading indicators, historically there is a range of lead times between the indicator and the target variable (Australian employment in the case of the DEEWR Leading Indicator of Australian employment). Assuming that the lead time reverts to its historical mean, it is probable that in future, the lead time of the Leading Indicator will be longer than at the most recent turning point.

Notwithstanding this, a short examination was conducted to attempt to explain and begin to rectify this short lead time. An examination of the lead times between the cyclical components of the four variables forming the Leading Indicator and Australian employment showed that the three components with the highest weightings in the Indicator had lead times that were the same as or similar to that of the Indicator itself, for the latest peak in cyclical employment. 
While the lead time for the Westpac-Melbourne Institute Consumer Sentiment Index is longer than other components or the Indicator itself at nine months, this series has the lowest weighting of all the components of the Indicator and there would be a risk in placing more reliance on this series in that historically its cyclical component has shown a number of false turning points of changes in cyclical employment.

Therefore, there does not appear to be any substantial benefit, in terms of improving the lead time to cyclical employment, in dropping one of the current components or changing the weighting of the components.

The performance of the Leading Indicator was examined in the context of the global financial crisis. As a result of this crisis, staff members of DEEWR (and many other organisations) are examining a wide range of economic and financial-market variables to investigate their links with employment, real GDP and other economic variables.

Some of these could not be formally analysed because a sufficiently long and consistent time series of data could not be obtained. However, it was possible to choose and analyse two of the most relevant series.

Two candidate series (US housing starts and the US median house price series) that are directly linked with the US housing downturn resulting from the Subprime mortgage problems in that country, which was a major cause of the global financial crisis, had quite different performance as a potential leading indicator of cyclical employment in Australia.

While these series do not relate solely to the US Subprime mortgage market, but are also affected by development in the US prime mortgage market, there would be a risk in using variables that are solely related to the US Subprime mortgage market (such as default rates on loans in this market). This is that while such indicators might accurately reflect the initial causes of the current global financial crisis, they might not be useful for predicting the flow-on effects of future major economic developments. In other words, policies and procedures might be set in place to prevent another US subprime mortgage meltdown, but there could be future international financial crises arising from other causes. However, more general measures of the US housing market were considered to be worthy of examination, given the size of the US economy, the importance of housing in that country and the tendency for economic developments to spread from the USA to Australia.

The US median house price series was found to be unpromising as a potential leading indicator of Australian employment at the current time, as it had a poor matching of cyclical amplitudes, inconsistent lead times and too many false signals of turning points.
It was considered that there would be other indicators of the global financial crisis that would also be unpromising for similar reasons. Indeed, for some of the most telling indicators of the global financial crisis, such as some of the interest rate spread series, the most dramatic changes did not occur until after the peak in Australian cyclical employment in April 2008.

One indicator of the global financial crisis, however, is showing good potential as a leading indicator of cyclical employment in Australia. This is the number of housing starts in the USA. The cyclical component of this series has, since early 1991 , had a fairly consistent lead time of around $1 \frac{1}{2}$ to $1 \frac{3 / 4}{4}$ years with cyclical employment in Australia.

While it would be problematic to attempt to include most offshore indicators of the global financial crisis in the DEEWR Leading Indicator of Employment at this stage, there are a number of series, including US housing starts, that are worthy of further consideration. It will, of course, be necessary to monitor separately a wide variety of other variables related to the global financial crisis for their potential effects on Australian employment.

\section{Notes}

1. This paper reflects the author's views and does not necessarily represent those of the Department of Education, Employment and Workplace Relations or the Australian Government. Nick O'Gorman provided invaluable research assistance in the drafting of this paper. Data up until 4 December 2008 were used in the analysis

2. The Leading Indicator shown in this Chart is made up entirely of the historical values of the current (new) Indicator. It does not contain a mixture of values of the previous (old) Indicator till June 2007 and those of the current (new) Indicator afterwards.

3. The TED spread is an indicator of perceived credit risk in the general economy. This is because the Treasury-bills are considered risk-free while LIBOR reflects the credit risk of lending to commercial banks. When the TED spread increases, this is a sign that lenders believe that the risk of default on inter-bank loans (also known as counterparty risk) is rising. Inter-bank lenders therefore demand a higher rate of interest to compensate for holding this higher level of riskiness, or accept lower returns on safe investments such as US Treasury-bills. Conversely, when the risk of bank defaults is considered to be decreasing, the TED spread decreases. TED is an acronym formed from Treasury-Bill and ED, the ticker symbol for the Eurodollar futures contract. The size of the spread is usually denominated in basis points (bps). 
4. Connolly G., Lee, J. And Stevens, L., Information on the New DRWR Monthly Leading Indicator of Employment, Department of Employment and Workplace Relations, Canberra, 11 July 2007.

\section{References}

ABS (2008), Labour Force Australia, Preliminary, October 2008, Catalogue No. 6202.0 (and previous issues).

Connolly G. and Lee, J. (2005), Review of the DEWR Leading Indicator of Employment, A Paper prepared for Presentation at the Australian Labour Market Research Workshop 2005, Australian National University, Canberra, 5-6 December.

Connolly G., Lee J. \& Stevens L. (2007), Information on the New DEWR Monthly Leading Indicator of Employment, Department of Employment and Workplace Relations, Canberra, 11 July, downloadable from www.workplace.gov.au/NR/rdonlyres/8B67F7F21CF2-49E6-88B3-

04C4FDE4C095/0/InfoPaperMTLIOE.pdf.

\section{Authors}

Greg Connolly

Research Analysis and Evaluation Group

Department of Education, Employment and Workplace

Relations

GPO Box 9879

Canberra City

ACT 2601

Australia

Greg.Connolly@deewr.gov.au

Jan Lee

Research Analysis and Evaluation Group

Department of Education, Employment and Workplace

Relations

GPO Box 9880

Canberra City

ACT 2601

Australia

Jan.Lee@deewr.gov.au

\section{Appendix}

\section{DEEWR Leading Indicator of Employment: Data sources, concepts and methods}

In this Appendix, the sources of the data series used in this paper, and the methods used to construct the series, are explained.

\section{The DEEWR Leading Indicator of Employment (LIoE)}

The LIoE is produced monthly. It is based on four weighted time-series variables, which are conventionally viewed as partial forward indicators of changes in cyclical employment.

The LIoE is a technical (rather than a fundamental) indicator in that component series are chosen on the basis of predictive performance and not the extent to which they represent fundamental or structural economic relationships.

The weighting of the component series is determined by regression analysis of the time-series data. The Leading Indicator incorporates data lagged one year for the Dun and Bradstreet Employment Expectations series and the most up to date data for the other series. This is based on econometric testing which revealed that the Dun and Bradstreet series had a longer lag. The name of the issue, and the labels for the $\mathrm{x}$-axis of the chart, relate to the month the Indicator is released. The data used to derive the cyclical employment chart line, however, are two months behind the Indicator release month.

The four components jointly contributing to the LIoE are:

1. ANZ Newspaper Job Ads from ANZ Job Advertisements Survey (monthly, seasonally adjusted);

2. Dun and Bradstreet Employment Expectations from Dun and Bradstreet Business Expectations Survey (monthly, seasonally adjusted);

3. Westpac-Melbourne Institute Leading Index of Economic Activity Survey (monthly, seasonally adjusted); and

4. Westpac-Melbourne Institute Consumer Sentiment Index Survey (monthly, seasonally adjusted).

\section{Estimation Methodology}

The time series of each of these four components, together with the employment time series, can be decomposed into the seasonal, trend, cyclical and irregular elements. The following steps are involved in the process of extracting the cyclical elements of these series and combining the weighted cyclical elements of the various component series to form the Indicator, which is then compared with the cyclical element of employment. 
The component series and the employment series are smoothed using 13-term Henderson weights to remove their irregular elements. This provides the one-year trend employment level.

The resulting series are then exponentially extrapolated both forwards (and backwards where necessary), using an average compound growth rate for the preceding five years, for 36 monthly observations and the trend elements are calculated as 73-term centred moving averages. This process allows us to obtain the six-year trend employment level.

3. The cyclical elements of the series are obtained by subtracting the six-year trend level from the oneyear trend level of each series.

4. The cyclical elements are then obtained by subtracting the mean from each series (to standardise it) and then normalising them by dividing by each series' standard deviation.

5. The partial forward indicators' components are combined linearly, applying weights obtained through econometric regression (see next section).

6. The Indicator is then obtained by dividing the combined set of components by its standard deviation.

\section{Determining the Weightings for each Component Series}

A regression analysis is performed (in December or January of each financial year) on the series in order to determine the weightings for the component series that is best capable of leading employment. The regression results are then standardised, by constraining the series to equal 1 (i.e., dividing each coefficient by the total of all coefficients) and the latest results are shown in the table below.

\section{Weights of the components series of the new leading} indicator:

\begin{tabular}{|l|c|}
\hline Series & Weights (\%) \\
\hline ANZ Newspaper Job Ads & 44.3 \\
\hline $\begin{array}{l}\text { Dun and Bradstreet Employment } \\
\text { Expectations }\end{array}$ & 22.4 \\
\hline Leading Index of Economic Activity & 24.1 \\
\hline Consumer Sentiment Index & 9.2 \\
\hline
\end{tabular}

\section{The estimated LIoE and its Relationship to Cyclical Employment}

On this basis, the DEEWR Monthly Leading Indicator of Employment is designed to provide advance warnings of turning points in cyclical employment. The average lead time for the Indicator (i.e., the time between a peak or trough in the Indicator and the corresponding peak or trough in cyclical employment) is estimated to be around nine months (or about twelve months if account is taken of the additional twelve-month lag in the Dun and Bradstreet Employment Expectations Index), although this has varied significantly over the past decade.

A 'turning point' in the Indicator is said to be confirmed when there are six consecutive monthly movements in the LIoE the same direction after a turning point occurs. Importantly, a fall (or a rise) in the Indicator does not necessarily mean that the level of employment will subsequently fall (or rise). Rather, it implies that after a lag, the growth rate of employment may fall below (or rise above) its trend rate of about 2.4 per cent a year (in November 2008).

Users of the Indicator must also be aware that the historical relationships between the LIoE and employment can vary from time to time. Therefore, judgements about the future levels of (and changes to) employment derived from the LIoE should therefore be qualified appropriately. The history and processes involved in the development of the LIoE are documented in a separate paper.

In Section 4 of this paper (with the heading The Global Financial Crisis) two other component series, which reflected the global financial crisis, were investigated to assess how their cyclical components line up with the cyclical component of employment in Australia and to consider whether they would be useful in adding to a possible new version of the LIoE.

The two component series are:

1. The monthly average (median) house price in the US (monthly); and

2. US Housing Starts (monthly, seasonally adjusted).

As with the four main components of the LIoE, the data for these two new components are subject to the same process defined under the section Estimation Methodology on pages 12 and 13. Unlike the four main components of the LIoE, they are neither weighted nor lagged. The two charts on pages 8 and 9 show the cyclical component of the monthly average (median) house price in the US and that for US housing starts, lining up with the cyclical component of employment in Australia. 